\title{
Dá tamaquaré pra ele! Humanos e animais entre poder e humilhação na Amazônia Paraense
}

Give him "tamaquaré"! Humans and animals between power and humiliation in the Pará State, Amazon, Brazil

\section{Bruno Rodrigo Carvalho Domingues}

\section{(2) OpenEdition}

Edição electrónica

URL: https://journals.openedition.org/aa/8913

DOI: $10.4000 / a a .8913$

ISSN: 2357-738X

\section{Editora}

Programa de Pós-Graduação em Antropologia Social (UnB)

\section{Refêrencia eletrónica}

Bruno Rodrigo Carvalho Domingues, «Dá tamaquaré pra ele! Humanos e animais entre poder e humilhação na Amazônia Paraense », Anuário Antropológico [Online], v.46 n.3 | 2021, posto online no dia 28 setembro 2021, consultado o 06 outubro 2021. URL: http://journals.openedition.org/aa/8913 ; DOI: https://doi.org/10.4000/aa.8913

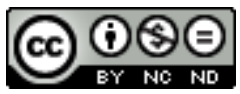

Anuário Antropológico is licensed under a Creative Commons Atribuição-Uso Não-Comercial-Proibição de realização de Obras Derivadas 4.0 International. 


\section{Anuário Antropológico}

v.46 n.3 | 2021

2021/v.46 n.3

\section{Dá tamaquaré pra ele! Humanos e animais entre poder e humilhação na Amazônia Paraense}

Give him "tamaquare'! Humans and animals between power and humiliation in the Pará State, Amazon, Brazil

\section{Bruno Rodrigo Carvalho Domingues}

\section{OpenEdition \\ Journals}

\section{Edição electrônica}

URL: http://journals.openedition.org/aa/8913

DOI: $10.4000 / a a .8913$

ISSN: 2357-738X

\section{Editora}

Programa de Pós-Graduação em Antropologia Social (UnB)

\section{Referência eletrônica}

Bruno Rodrigo Carvalho Domingues, «Dá tamaquaré pra ele! Humanos e animais entre poder e humilhação na Amazônia Paraense», Anuário Antropológico [Online], v.46 n.3 | 2021. URL: http:// journals.openedition.org/aa/8913 ; DOI: https://doi.org/10.4000/aa.8913

\section{(c) $($ i) $($ )}

Anuário Antropológico is licensed under a Creative Commons. Atribuição-SemDerivações-SemDerivados CC BY-NC-ND 


\section{Dá tamaquaré pra ele! Humanos e animais entre poder e humilhação na Amazônia Paraense ${ }^{1}$}

Give him "tamaquare"! Humans and animals between power and humiliation in the Pará State, Amazon, Brazil

DOI: https://doi.org/10.4000/aa.8913

\section{Bruno Rodrigo Carvalho Domingues}

Universidade Federal do Rio Grande do Sul, Instituto de Filosofia e Ciências Humanas,

Programa de Pós-Graduação em Antropologia Social, Porto Alegre, RS, Brasil.

Mestrando em Antropologia Social pelo Programa de Pós-Graduação em Antropologia Social da Universidade Federal do Rio Grande do Sul. Bolsista da Comissão de Aperfeiçoamento de Pessoal de Nível Superior - CAPES.

Neste artigo, analiso o que chamei de cosmoerotismo amazônico, uma forma particular de acesso ao cosmos para a interferência na vida afetivo-sexual dos seres humanos na Amazônia Paraense, especialmente na cidade de Abaetetuba, por meio do uso de "patuás" para o amor e para o sexo, confeccionados a partir da interação entre humanos, animais, plantas e caboclos. 0 uso dos patuás acarreta algumas consequências, dentre as quais a humilhação, aqui analisada à luz de teóricos que acionam essa emoção hostil, ancorados nas relações de poder. Os resultados apontam para a formação de complexos emocionais desenvolvidos a partir da relação entre humanos e não humanos.

Cosmoerotismo Amazônico. Poder. Humilhação. Diversidade Sexual e de Gênero.
In this article I analyze what I called Amazon cosmoerotism, a particular form of access to the cosmos for interference in the affective-sexual life of humans in the Para State, Amazon - Brazil, especially in the Abaetetuba City, based on the use of "patuás" for love and for sex, made from the interaction between humans, animals, plants and caboclos. The use of patuás has some consequences, including the humiliation that will be analyzed using theorists who think this hostile emotion is anchored in power relations. The results point to the formation of emotional complexes developed from the relationship between humans and non-humans. 
Tayana recebeu uma encomenda ${ }^{2}$. Tratava-se de uma amiga que sofria por não se sentir desejada e buscava melhorar seu potencial de atração e desempenho sexual para assim ter todos os homens que quisesse aos seus pés. Para isso, decidiu recorrer à médium que prepara diversas poções para o amor e para o sexo. Tayana, que se afirma uma pessoa espiritualizada, é uma mulher transexual, experiente na feitura de trabalhos, patuás, amarrações e feitiços. Assim, logo atendeu a amiga, obedecendo bem às regras para o preparo de um patuá. Essas regras são as primeiras das várias normas para o uso de feitiços durante o ato sexual. Então iniciam a conversa entre cliente (quem procura por um patuá) e médium (quem o prepara). Tayana e sua cliente sentaram-se e conversaram sobre os problemas amorosos e sexuais da cliente, cujo nome não me foi revelado, mas que chamarei de Débora. Ela explicou por que busca satisfazer seus impulsos eróticos a partir da magia, e estes motivos se concentram em seu desejo de conseguir seduzir qualquer homem. Ela gosta da ideia de ver os homens desejando-a e da possibilidade de sair para uma festa e, sem dificuldades, conseguir todos aqueles que deseja.

Tayana explicou que, neste caso, não se trata de um feitiço de longo prazo, tampouco uma amarração, mas de um patuá atrativo: a confecção de um produto para uso pessoal, que pode ser um fluido, um sabonete, um perfume, um óleo, uma defumação, devendo ser aplicado nos órgãos genitais antes das relações sexuais ou em qualquer parte do corpo antes de ir ao encontro com a pessoa por quem sente desejo. $\mathrm{O}$ uso destes produtos na pele antes do encontro tem o potencial de atrair a pessoa desejada, enquanto o uso nas genitálias promove a sensação de que aquela experiência sexual é única, os orifícios aparentam ser mais apertadinhos para quem penetra, fazendo com que o/a parceiro/a queira fazer sexo mais e mais vezes com aquele/a que usa o produto. Tayana explica que não é tão simples quanto aparenta ser. Mais que confeccionar um fluido, é preciso compreender o que forma os poderes de atração e sedução destes e foi assim que Tayana marcou uma consulta às cartas para Débora. $\mathrm{O}$ objetivo era que as entidades mostrassem como andava a vida afetiva da cliente, pois a médium precisava ter certeza de que, caso ajudasse a amiga, não se arrependeria depois. Afinal, todo patuá tem também consequências, então é preciso que o cliente saiba exatamente o que quer.

Consulta feita. As cartas indicaram a Tayana que tudo estava indo bem na vida de Débora, e que ela estaria autorizada a ajudar a amiga. A médium então pede para que a amiga anote, num bloco de notas, o que será necessário para a preparação do patuá: neste caso, Tayana opta pelo sexo da bota, ou buceta da bota, indica algumas ervas de sua preferência, uma vela em formato de cachorro popularmente conhecida como "vela cachorrinho" e, para finalizar, pede que Débora colete os "pentelhos" de sua vagina. Assim, Tayana teria um "material espiritual" da cliente, que também seria inserido no patuá.

Nas palavras que seguem sintetizo os resultados de pesquisa de minha monografia do curso de Bacharelado em Ciências Sociais, onde cunhei o termo cosmoerotismo amazônico (Domingues, 2019) a fim de possibilitar a análise sobre as interações entre
1 Uma primeira versão deste artigo concorreu ao Prêmio Lévi-Strauss da Associação Brasileira de Antropologia no ano de 2020. Este texto contou com comentários/revisões de Artur Castilho, Camila Braz, Cleiton Rocha, Flávio Barros, Mariah Torres Aleixo, Pablo Quintero e Sofia Favero, a quem deixo aqui minha gratidão. Estendo meus agradecimentos também aos pareceristas anônimos da Anuário Antropológico, pelas excelentes sugestões, e à CAPES pela bolsa de estudos.

2 Todos os nomes elencados neste texto são fictícios para preservar a identidade dos/as interlocutores/as. 
humanos e não humanos em uma cidade no interior da Amazônia paraense para finalidades afetivas e sexuais. A anedota de abertura vem de uma das conversas que constam em meu diário de campo e a escolhi para iniciar este texto por sintetizar bem os resultados da pesquisa. Naquele momento, eu buscava compreender o uso de feitiços para o amor e para o sexo em uma cidade do interior da Amazônia paraense, Abaetetuba (Figura 1). Abaeté, como é popularmente conhecida, se situa às margens do Rio Maratauíra e é povoada por pouco mais de 100 mil habitantes, tendo sido famosa durante o século XX pelos muitos engenhos de cana que existiam ali, se tornando uma das principais produtoras de cachaça do país.

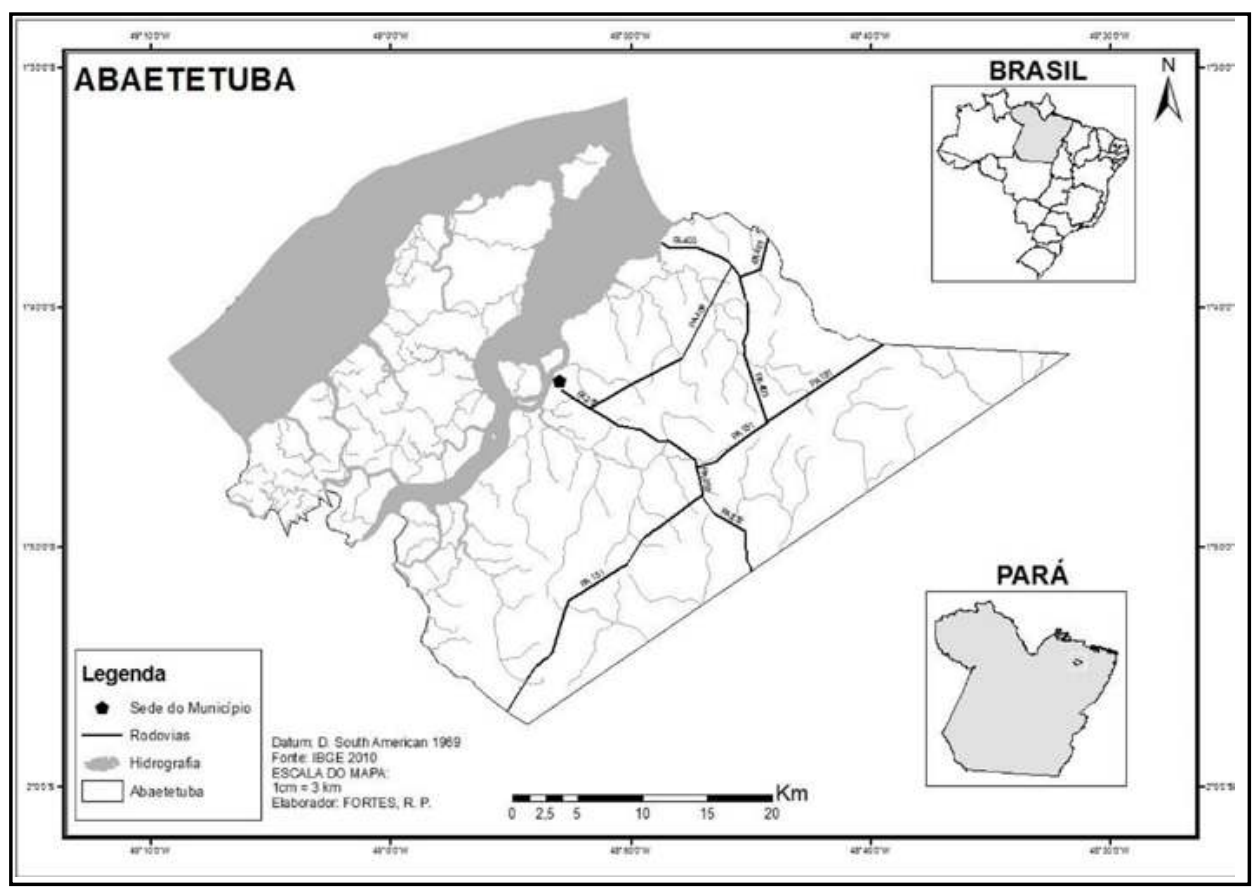

De lá para cá, muita coisa mudou. A cidade, que já foi predominantemente rural, ganha um forte núcleo urbano, se relacionando economicamente não mais com a produção de insumos alcoólicos, mas a partir do setor de serviços, comércios atacadistas e varejistas, sobretudo nas proximidades da "beira", como é conhecida a principal feira livre da cidade. Durante o século XXI, a cidade volta a aparecer no cenário regional, nacional e internacional, mas dessa vez como a "capital do brinquedo de miriti”, esculturas feitas com a medula do pecíolo de uma palmeira abundante na Região Amazônica, o miritizeiro (Mauritia flexuosa). A cidade, entre muitas poéticas traduzidas por seu intelectual mais famoso, João de Jesus Paes Loureiro, possui políticas e poéticas indizíveis: o erotismo, a busca pelos afetos e a magia.

Refiro-me ao uso de feitiços para atrair parceiros afetivos e sexuais, como os banhos de cheiros e o sexo do boto, que comumente são atribuídos apenas ao circuito mais famoso destes produtos: as erveiras do mercado do Ver-o-Peso, em Belém, capital do Pará. Sendo um antropólogo que nasceu, cresceu e viveu no interior da Amazônia até o momento em que precisou se deslocar em função das titulações acadêmicas, sempre estive em contato com Abaetetuba, seja por ser de família materna abaetetubense, seja por ter nascido e vivido na cidade vi-
Figura 1 - Mapa de Localização do Município de Abaetetuba - PA. 
zinha, Barcarena. Desenvolvo pesquisas nessa cidade desde quando iniciei a vida acadêmica, conhecendo desde as ilhas, ramais, estradas, e mesmo sua urbe, que defini como meu universo de pesquisa, dessa vez para analisar como feitiço, cosmologia, erotismo, gênero, sexualidade, emoção e poder operam no fazer social de uma cidade amazônica. Metodologicamente, a pesquisa foi conduzida a partir da observação participante (Malinowski, 1978) e espontânea, da coleta de dados etnoecológicos (Amorozo et al., 2002) e entrevistas abertas.

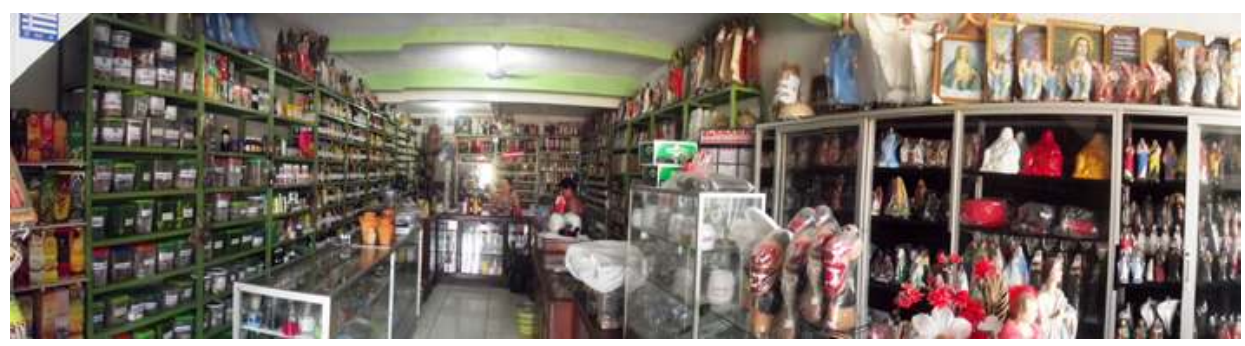

Esses ditos feitiços partem da comercialização de produtos da biodiversidade para o amor e para o sexo em cabanas, como são conhecidas as lojas de produtos religiosos (Figura 2) e estão espalhadas por diversos bairros de Abaetetuba. De tudo um pouco se comercializa nessas cabanas, sempre relacionado ao sincretismo religioso. Nas cabanas, há sempre uma prateleira grande com produtos relativos aos desejos (cosmo)eróticos: buceta da bota, pênis do boto, pó de tamaquaré, perfume da pomba-gira, chega-te-a-mim, agarradinho, velas em formato de santos e entidades (Figura 3a), genitálias (Figura 3b), animais (Figura 3c), entre muitos outros. Estes produtos são comprados por clientes que passam por demandas afetivas e sexuais, os quais podem ou não consultar um médium antes da compra. O médium é uma pessoa que se considera espiritualizada e entende sobre os preparos dos patuás, não necessariamente vinculado a uma religião ou a uma casa religiosa. São eles os responsáveis por consultarem o cosmos, que, por sua vez, dá o "aval" acerca do que é preciso comprar e a autorização para interferir na vida afetiva de outrem - os/as médiuns consultados/as sempre exigem o consentimento das entidades para a feitura do patuá.

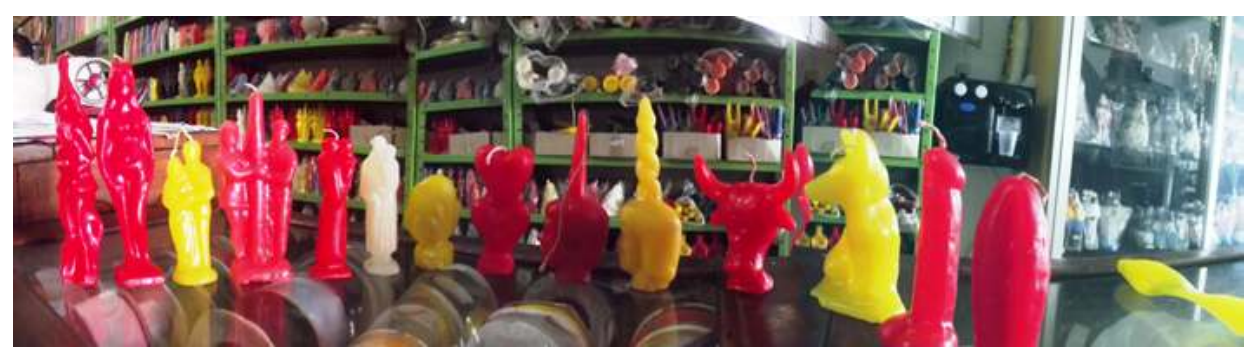

Figura 2 - Vista interna de uma "cabana" de produtos religiosos localizada em Abaetuba/PA.

Figura 3a - Velas coloridas em formatos diversos: encantados, santos católicos, animais e genitálias. 

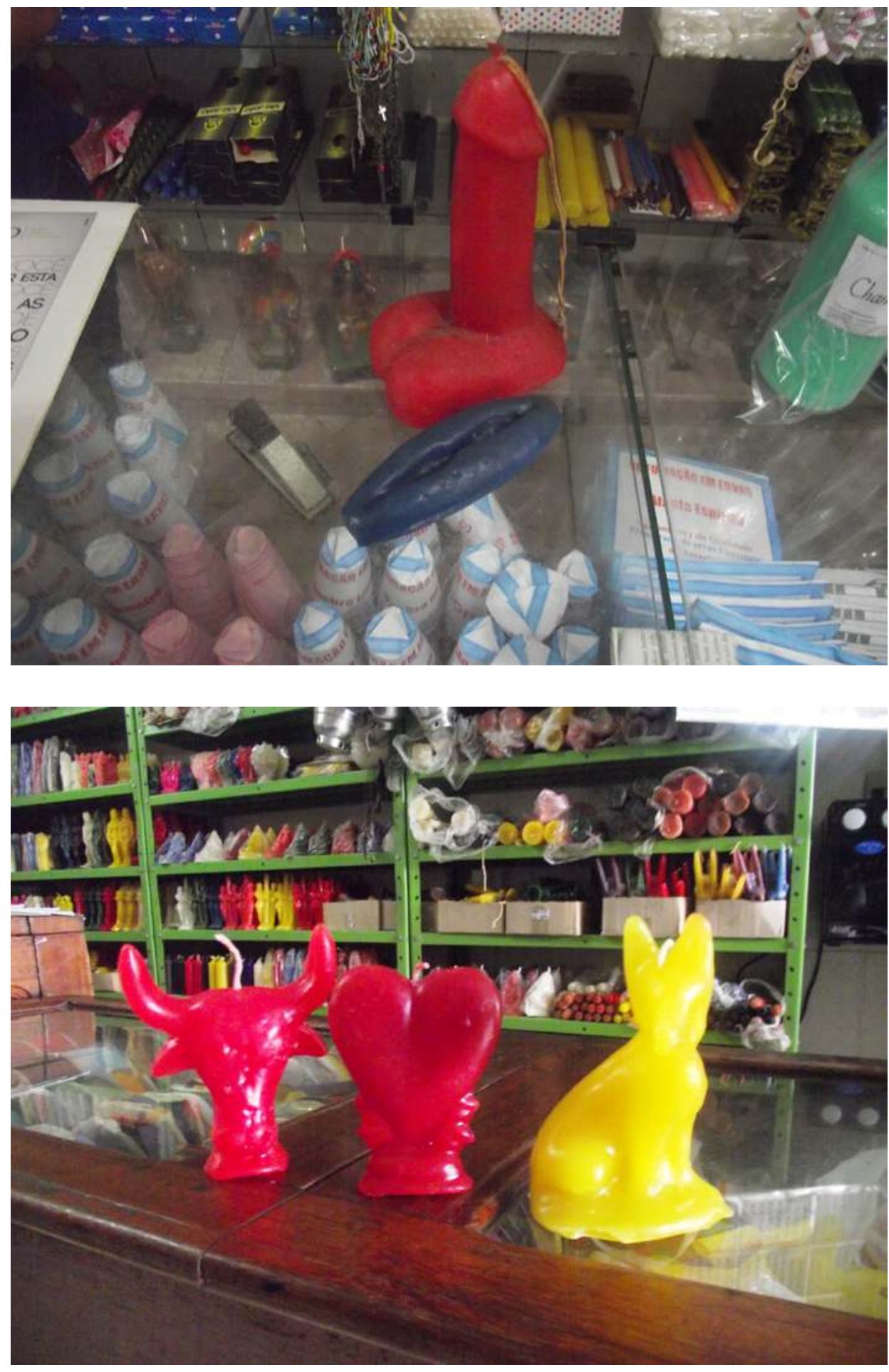

Os produtos comercializados nessa prateleira possuem as finalidades de: 1) atrair parceiros sexuais; 2) amarrar parceiros afetivo-sexuais para relacionamento duradouro; 3) repelir parceiros abusivos; 4) amansar o companheiro para melhorar a convivência ou facilitar traições; 5) vingar-se por ter amado em vão, entre tantas outras. A principal motivação para procurar um médium ou uma cabana, segundo os próprios médiuns, proprietários de cabanas, e de acordo com o imaginário social da urbe, é o sofrimento. Tal motivação pode não condizer com as expectativas dos próprios clientes, pois são tratados a partir da interpretação outra de seus sentimentos ${ }^{3}$.
Figura 3b - Velas coloridas em formatos diversos: falo e vulva.

Figura 3c - Velas coloridas em formatos diversos: animais (touro, cachorro) e coração. 
Os sofrimentos comumente elencados dizem respeito ao sofrer por não ser amado, não ter um par, ter sido traído, querer vingança. O/a cliente por vezes é estigmatizado pela sociedade abaetetubense como incapaz de relacionar-se "espontaneamente". Segundo os interlocutores ${ }^{4}$, os/as clientes estão em busca do alívio do sofrimento, agenciando o sofrer a partir do cosmos. Há muitas formas de buscar este alívio e embora haja um "roteiro" de procura ou mesmo consequências muito próximas, as formas como as relações são tecidas se diferem a partir das necessidades de uso dos feitiços.

Dentre os interlocutores desta investigação, Denis é um homem cisgênero ${ }^{5}$, branco, heterossexual, médium de orientação religiosa de Mina Nagô/Umbanda sendo filho de santo de um terreiro na cidade, no entanto, realiza pequenos trabalhos em sua própria residência, onde planejava um dia ter sua própria casa religiosa. Ellen é uma mulher cisgênera, negra, cozinheira e médium, filha de santo da mesma casa em que Denis é iniciado e, tal qual o médium, realiza pequenos trabalhos e sobretudo "bruxarias", como gosta de afirmar, em sua própria residência. Janaína é uma mulher cisgênera, negra, filha de médium e funcionária de uma cabana popular na cidade, fez uso de um banho de rosas para conquistar um namorado, mas não se considera uma cliente, pois não aciona constantemente esses produtos. Tayana é uma mulher trans, negra, se considera uma pessoa espiritualizada, transitou por diversas religiões até decidir trabalhar para o bem dos amigos. Os médiuns são um elo entre entidades, clientes e materiais dos feitiços; a eles cabe receitar os patuás atrativos para as conquistas afetivo-sexuais, como na anedota de abertura, e em cada elemento do feitiço a ser realizado há uma associação a elementos humanos e não humanos na busca da resolução dos problemas dos afetos entre humanos.

Se observarmos os detalhes da indicação da médium, o sexo da bota se trata da genitália da fêmea do Boto Tucuxi (Sotalia fluviatilis), que é cortada e defumada, comumente comercializada nas cabanas. $\mathrm{O}$ uso da genitália do animal está associado aos muitos dizeres, mitos e tabus que envolvem a figura do boto na Amazônia, sobretudo ao caráter sedutor do animal, que, na cosmologia amazônica, se transforma em humano e sai para dançar e seduzir jovens mulheres de comunidades rurais, ribeirinhas e interioranas, fazendo com que elas passem a carregar em seu ventre um "filho do boto". A criança que nasce nessas comunidades sem a figura do pai presente é associada ao parentesco com o delfim da Amazônia.

Já quanto aos materiais espirituais, Tayana recomenda que se retirem partes do corpo humano que crescem constantemente, como cabelos, pentelhos, unhas, pelos e, portanto, materiais puros, e que se evitem os materiais espirituais impuros: esperma, sangue menstrual, suor, pois estes são elementos que nosso corpo descarta, que apodrecem se mantidos fora do organismo. Como esses fluidos perecem, o potencial de atração também seria apodrecido, morto, prejudicando assim o uso e para além, gerando consequências irreversíveis a quem usa e também a quem é "enfeitiçado", pois os fluidos corporais possuem forças que a médium não pode deter.

Todo patuá é um feitiço, podendo gerar consequências que podem ser negati-
4 Na primeira etapa da pesquisa, não foi possível entrevistar os clientes, devido aos tabus sobre o uso dos produtos. Explico: não se pode dizer que faz uso destes produtos, para que eles não percam os efeitos; assim, não foi possível acessar os clientes. Contudo, na atual etapa da pesquisa, os clientes foram ouvidos. Não apresento tais dados neste escrito por questões éticas: a pesquisa é desenvolvida em outra instituição e a partir de outras prerrogativas que não necessariamente as que socializo aqui.

5 Mais do que um indivíduo que se identifica com o gênero imposto ao nascimento, tendo como base o sexo biológico, uma pessoa cisgênera partilha de um sistema (ou CIStema) de poder que constitui as arquiteturas hierárquicas e colonialistas estabelecidas no curso da história e da subjugação dos grupos sociais a partir de uma norma, de um padrão de humanidade. Para uma boa discussão sobre cisgeneridade, consultar a dissertação de mestrado de Viviane Vergueiro (2016). 
vas para quem faz o uso, pois mexe com forças do cosmos, sendo a principal consequência a humilhação de outrem ou a própria humilhação. Explico: humilhar a outrem é a possibilidade de a pessoa enfeitiçada ser difamada na cidade quando se tem notícias de que foi vítima de feitiço; humilhação de si se dá quando a pessoa que faz uso destes produtos é vista pela sociedade abaetetubense como alguém fracassado que não consegue, pelas vias ditas normais, conquistar parceiros afetivos e sexuais, ou vista como promíscua, pois a busca por melhorar o potencial de atração para sexo casual é recebida pelos citadinos como um elemento que atesta a vulgaridade e a prostituição no imaginário popular sobre a vida sexual das mulheres abaetetubenses.

Humilhação opera aqui seja como objetivo do ato de rebaixamento, seja com o mau uso de um patuá. Ambos acarretam consequências sentidas dentre os espaços de sociabilidades que os indivíduos frequentam e variam de acordo com os marcadores sociais da diferença que compõe estes indivíduos.

\section{Uma Amazônia cosmoerótica}

As sociedades amazônicas são sociedades complexas e possuem configurações próprias de mundo, como podemos observar no trabalho de Maíra Melo e Flávio Barros (2016, p. 125-126), no qual apresentam a tridimensionalidade do mundo quilombola na Amazônia, dividido em "mundo dos espíritos", "mundo dos vivos" e "mundo dos encantados", e nos escritos de Harris (2004) apud Albuquerque e Faro (2012, p. 62), em que, na realidade das encantarias amazônicas, "o mundo dos homens seria interligado pelo Céu e pelo Fundo". Segundo Raymundo Heraldo Maués (1995), há nessa forma de pensar o mundo, as concepções católicas de céu-inferno, em que no céu se resguarda o paraíso dos cristãos, servos de Deus, enquanto o inferno se apresenta como oposição ao paraíso. Contudo existe, entre esses planos, o "fundo", onde habitam os encantados, ou seja, seres que não experimentaram o morrer, mas se encantaram e hoje habitam as profundezas dos rios, matas, cidades, habitando imaginários e protegendo territórios. Há seres humanos que conseguem interseccionar esses mundos, seriam as figuras dos pajés, sacacas e outras denominações. Tal conformação de mundo sugere pensar que a forma como as pessoas o habitam pode ter outras conotações que não as daquele mundo dualista, da oposição céu-inferno.

Sugiro pensar o cosmoerotismo amazônico como o conjunto de signos entre humanos e não humanos (animais, encantados, espíritos e demais seres cósmicos) que moldam as relações amorosas e sexuais, não no sentido de analisar o amor dos humanos e não humanos entre si, mas como humanos recorrem aos não humanos para o atendimento aos seus impulsos eróticos. O cosmoerotismo amazônico, em meu entender, é o momento em que se recorre a - ou se ativa - uma perspectiva cósmica amazônida de alcançar o amor ou o prazer, num processo multilateral, pois, ao mesmo tempo em que os humanos acessam o cosmos, o cosmos experimenta novamente as relações humanas. 
Eduardo Galvão (1955) aponta que os olhos do boto funcionam como um amuleto que atrai o amor, também sendo utilizado na elaboração de feitiços. Napoleão Figueiredo (1994), quando escreve sobre bichos que curam, aponta o erotismo por trás da figura do boto na Amazônia. Flávio Barros (2016) relata um “causo” de um pescador que foi encantado pela "bota", e que teria transado com ela, o que causa estranheza em alguns leitores, haja vista que os mitos amazônicos relatam o boto sempre em figura masculina que sai da água com porte elegante, vestido de branco, com um chapéu na cabeça, e seduz mulheres em festas, encantando-as e engravidando-as, e posteriormente parte para o rio quando novamente retorna à forma antiga.

Luisa Elvira Belaunde (2015 p. 552) também aponta a existência de relatos sobre "mulheres-boto namorando homens". Fazendo menção ao folclorista Câmara Cascudo, Belaunde (2015 p. 552) diz que "na beira dos grandes rios navegáveis da Amazônia brasileira, existia a lenda popular de que os botos habitam grandes cidades debaixo da napa dos rios. Nesse mundo subaquático, eles possuem tecnologias modernas e seus corpos são belos e sedutores".

Durante a minha primeira aproximação ao campo desta pesquisa, os interlocutores iniciais diziam que o boto é uma figura sedutora e que está muito próxima dos humanos. A vulva da bota (ou sexo, xiri e buceta, como preferem) é similar à vulva da mulher cisgênera e por isso alguns pescadores, quando passam longos períodos distantes da terra firme, transam com as botas que capturam durante as atividades de pesca - algo que um dos entrevistados também me contou em forma de "lenda":

Dênis: Você sabe a lenda da bota como aconteceu?

Bruno: Da bota não, só do boto.

Dênis: Como é a do boto?

Bruno: Um boto que se transforma em homem bonito que vai para as festas namorar as meninas ribeirinhas...

Dênis: Não, não! Esse é um sentido folclórico do boto, o boto é um encantado, ele vai nos terreiros de mina, ele é uma entidade, meu pai mesmo ele recebe o boto branco... [...] Tem também a outra lenda folclórica de que um pescador esticou sua rede assim, no rio, e aí uma bota ficou presa lá na rede... Quando ele foi tirar, ele viu que o sexo da bota era idêntico ao da muIher e ele resolveu ter relações com a bota e ele morreu em cima dela de tão gostoso e tão parecido que era (Entrevista com Dênis, setembro de 2017).

O boto opera de modo a "avivar" a potência sexual de quem entra em contato com esse animal/encantado, tal qual já havia sido apontado por Jerônimo Silva (2014) e não é o único mito na Amazônia que erotiza suas personagens. Quando pensamos na figura da Iara, uma sereia que encanta pescadores com sua beleza e canto, percebemos esta erotização, assim como quando pensamos no mito do Ataíde, definido como um "monstro" protetor dos manguezais dotado de enorme pênis, utilizando-o para espantar aqueles que destroem os mangues. Este ser mí- 
tico aparece nas narrativas orais de diversas comunidades na região do Salgado Paraense, fazendo uso da sua gigantesca condição fálica para deflorar homens e mulheres que promovem atrocidades à natureza. Comumente, a homossexualidade masculina nesta região pode ser associada aos imaginários sobre o Ataíde (Silveira; Souza, 2014).

Quando João Jesus de Paes Loureiro analisou a cultura amazônica, definiu-a como sendo permeada por imaginários em grande parte erotizados (2001), repletos de signos/símbolos que se converteram semioticamente de acordo com o meio, mudando de função (2007). Se a conversão semiótica é o processo pelo qual um aspecto da cultura amazônica é materializado em outro signo, os produtos comercializados em cabanas e que provêm do contato com o imaginário erotizados poderiam nos sugerir outras relações quando operados no cotidiano.

Bruna Bitencourt, Glécio Lima e Flávio Barros (2014) desenvolveram pesquisa de campo no Mercado Público do Guamá, em Belém/PA, onde encontraram diversos produtos, como "buceta da bota", olho do boto, tamaquaré (pequeno lagarto da espécie Uranoscodon superciliosus), jiboia (família de serpentes), entre outros, sendo comercializados pelos feirantes e amplamente recomendados para "amansar" ou "atrair" parceiros. A associação das genitálias de animais a problemas de ereção masculina ou falta de libido feminina também foi sinalizada por Fraxe (2004) e Barros et al. (2012). Débora Lopes (2015) analisa usos da biodiversidade capazes de "levantar a moral do homem", que precisam ser tratados com técnicas específicas para que funcionem como estimulante sexual masculino, com rituais de extração e preparo fundamentais para o bom funcionamento dos estimulantes.

Existe ainda uma vasta produção em antropologia amazônica que dá conta de um universo onde se tem uma forte presença religiosa - pelo catolicismo popular, ou as religiões de matriz africana -, uma forte correlação entre gênero e tabus de sangue ou conhecimento tradicional entre mulheres para os cuidados íntimos, como os estudos de Maués (1995), Figueiredo (1996), Motta-Maués (1994) e Pinto (2004). Tais estudos sugerem interações entre os mundos nessas Amazônias interseccionadas por noções de cosmologia ou de conhecimentos tradicionais/ ancestrais, sendo pertinente associar tais noções às atividades de regulação dos códigos morais, satisfação no campo afetivo-sexual, alívio do sofrimento, relações de poder, com consequências a serem estabelecidas no jogo das dinâmicas sociais, o que se pretende com este escrito.

\section{Do desejo à humilhação e o desejo por humilhação}

Ao buscar por Tayana para resolver um problema relacionado ao "sofrimento por não se sentir desejada", mais do que fortalecer o self a partir de um produto (cosmo)erótico, Débora busca poder de "ter qualquer homem aos seus pés", mostrando que na lógica desta procura se situa também a busca pela dominação e pela inversão dos papéis sexuais histórica e socialmente construídos de que homens dominam/detêm o controle em uma sociedade fundada no machismo e no heteropatriarcado. Esta busca pela inversão das posições desiguais também é reforçada
6 Na noção de Erving Goffman (2009). 
quando, para isto, se utilizam velas em formato de cão a fim de docilizar homem, e termos como "ter aos meus pés", ou ervas com nomes que também evocam o caráter de dominação, como "chora nos meus pés". Fica nítido que o que se busca é inverter as lógicas de submissão e dominação, de modo a colocar aquele que foi construído enquanto sujeito universal e dominante sob o domínio de quem foi construído como frágil, vulnerável, dócil.

No entanto, a subversão escancarada à norma se dá somente na esfera da vida privada, pois a lógica do segredo é impetrada também seguindo a construção social das desigualdades produzidas pelo sexo, alguém que busca por estes feitiços é visto pela sociedade abaetetubense a partir de estigmas impregnados - na noção de Erving Goffman (1988) - que giram entorno não somente da imagem de incapaz de conseguir um amor pelas vias ditas normais, mas, quando mulheres, também da promiscuidade, uma vez que o principal estigma associado à busca por feitiços para o sexo e não para o estabelecimento de amores duradouros é o da prostituição:

Quem mais utiliza os produtos com finalidades apenas sexuais são as muIheres da vida, prostitutas. Elas buscam esses produtos para atrair mais clientes. Só que isso é muito perigoso porque, por exemplo, tem mulher que chega comigo e diz que quer fazer uma defumação de sexo da bota no xiri, isso é um perigo, a defumação cura aquela vagina pra sempre, o homem que comer essa mulher vai virar um patinho, um pateta. Muitas prostitutas fazem isso para conseguir fidelizar determinados clientes que elas sabem que têm dinheiro, é muito perigoso, o cara vira um zé buceta, só faz o que ela quer, dá tudo o que ela quer. Isso aliado ao perfume do tamaquaré, Deus o livre... (Entrevista com Denis, setembro de 2017).

Há um estigma inerente ao uso dos patuás com finalidade sexual por parte das mulheres, ainda que não se conheça ao certo a motivação do uso. Abaetetuba é uma cidade cujo cotidiano, segundo Lucielma Silva (2013, p. 45-46), é marcado por práticas machistas, em que as mulheres que optam por não estabelecerem casamentos são comumente vistas a partir da figura das "solteironas" e "coitadinhas", havendo forte estímulo ao matrimônio. No quesito vida financeira, as mulheres do município ocupam empregos com maior remuneração que os homens, mas quando Silva realizou sua pesquisa, ainda era comum encontrar casos em que eram os maridos que administravam os rendimentos das esposas.

Os patuás atrativos devem ser utilizados em segredo, pois a descoberta de que uma mulher faz uso dos patuás acaba por sujeitá-la a diversos constrangimentos cotidianos, como as fofocas ou a distorção de sua liberdade sexual, visto que, na própria fala de Dênis, percebe-se uma forte associação dos atrativos a prostituição, gerando comentários.

Janaína: Todo mundo ficava falando, minhas amigas namorando e eu não, 
daí a minha mãe ficava "ô minha filha toma um banho de rosas pra ver se tu desencalha", eu fiquei depois com aquilo na cabeça, com o tempo todo mundo cobra que a gente tenha alguém, então eu vim aqui pro trabalho e a Zilda me deu uns banhos. Passou assim um mês apareceu um menino na praça querendo me conhecer, daí eu aceitei e a gente tá com 4 meses agora.

Paira na urbe certa moralidade que circunscreve as mulheres em ideais de representação de acordo com o tipo de atrativo: se atrativo sexual, associação a prostituição; se banho de rosas, associação a uma imagem romântica e estática de mulher, aprisionando-as em formas únicas e essencializadoras. $O$ jogo do segredo, além de permitir a fuga dessas imagens externas, influi em outros fatores da dinâmica social. Por um lado, o segredo deve ser mantido para que a honra do/ da cliente não seja maculada, e, por outro, para que o patuá funcione e o feitiço não seja quebrado.

Se por um lado a mácula da honra feminina está na atribuição da prática a imagens essencializadas, o rebaixamento da honra dos homens geralmente ocorre em função de serem tidos como "alvos" dos feitiços e associações à domesticação e docilização na relação com suas parceiras. A domesticação vem imbuída de atribuições a priori não humanas a esses homens, comparações com animais ou apelidos que os comparam com seres inanimados. Jan Smedslund (1997) afirma que a humilhação é uma emoção hostil que representa a violação mais profunda da dignidade pessoal do ser humano, processo que, para Ana Vicentini Azevedo (2005), baseia-se no rebaixamento do sujeito ao nível de um objeto.

O homem acometido por um patuá atrativo é visto na sociedade abaetetubense como um canoa, termo utilizado para designar um homem que vive sob as ordens de sua esposa, precisam ser "remados", "pilotados" por elas, por isso a comparação ao objeto. As mulheres dos homens-canoas geralmente são acusadas de utilizar estes produtos, seja esta uma acusação real ou não. Canoa se tornou apelido, por exemplo, de homens e mulheres que, ao serem convidados a algum evento com amigos de uma das partes de um casal, primeiro pedem permissão do/a companheiro/a.

No que diz respeito aos materiais utilizados na feitura de um patuá, muitos deles são de origem animal, como o pó do tamaquaré, o pó do jabuti (Chelonoidis carbonaria) (Figura 4), a atração ${ }^{7}$ da bota e do boto (Figura 5), a água da jiboia, mas podem ter origem vegetal ou representar elementos da animalidade, muito presente também nos nomes das velas e plantas, como "cachorrinho", "touro manso", entre outros. A lógica que opera aqui diz respeito às relações de poder e das relações entre humanos e não humanos (animais e/ou entidades) ${ }^{8}$ no sentido de que quanto maior for a humanidade atribuída aos animais, maior é a possibilidade de ele atender aos desejos dos humanos, mas não somente. É necessário que, dentre as formas de humanidade atribuída a estes animais, esteja o poder.

\footnotetext{
7 O mesmo patuá recebe vários nomes - atração, gostosinho, sexo, óleo, perfume do boto ou da bota - bem como as versões mais populares no fazer social, como xiri da bota, buceta da bota, pênis do boto, de modo que se confere maior humanidade a esses animais.

8 Utilizo as noções de humanidade e animalidade de Tim Ingold (1994).
} 

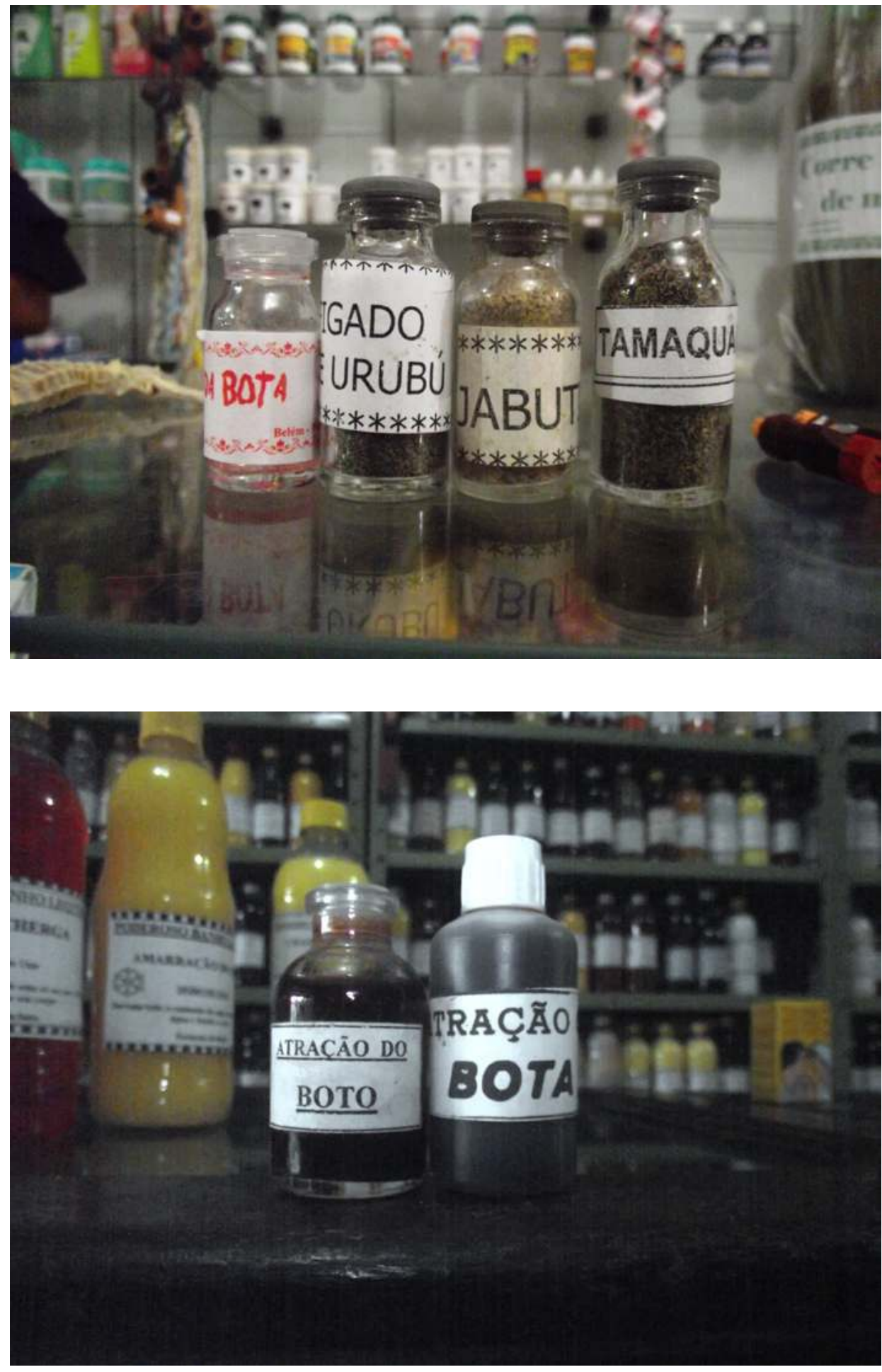

Há, para o cosmoerotismo amazônico, duas formas de se estabelecer a humanidade em um animal: auferindo caracteres positivos ou negativos. Ambos operam a fim de satisfazer a manutenção das relações de desejo sexual e poder. Assim, quando se utiliza o tamaquaré, o jabuti, o uruá (caracol da família Lymnaeidae) ou o ambuá (Classe Diplopoda) na feitura de patuás, se usa porque, na relação com os humanos, eles demonstram estar sempre medrosos, frágeis, fingem-se de mortos, escondem-se dentro de cascos ou conchas e são facilmente capturados. Ao longo do trabalho de campo, foi comum deparar-se com discursos como os de que esses animais são "bobos", "patetas", "trouxas", o que também acontecia com animais
Figura 4 - Da esquerda para a direita: Sexo da Bota, Pó do Fígado do Urubu, Pó do Jabuti e Pó do Tamaquaré.

Figura 5 - Sexo da Bota e do Boto, engarrafados em pequenos frascos. 
domésticos, como os cachorros que "vão nos braços de qualquer um", "são fiéis e bobos" ou "quando levam bronca abaixam a cabeça ou escondem-se entre as pernas de seu dono". Quanto ao boto e à bota, a relação é de sedução e erotismo já fortemente presentes no imaginário amazônico.

As características auferidas a estes animais, porém, não necessariamente dizem respeito à unidade biológica que compõe seus organismos, mas à atribuição de características a priori animais, porém construídas nas relações sociais. Um jabuti não se esconde no casco porque é bobo, mas porque se sente ameaçado por um predador dentro de seu ciclo biológico. Assim, a relação de poder entre humanos e não humanos se estende para as relações entre humanos, não na perspectiva de obter animalidade, mas de tomar novamente para si a humanidade que foi auferida a estes animais no fazer social.

Quando Tayana orienta que é necessário "domar" a pomba-gira, implica em estabelecer ali uma relação com o cosmos que não vê as entidades como seres supremos e dotados de soberania, mas como sujeitos cósmicos que já experienciaram as relações humanas (quando frisa que pombas-giras são da falange da malandragem) e que, portanto, devem ter as relações com o erotismo negociadas num jogo que nem sempre é igual. A desigualdade não se espraia apenas sobre os seres humanos, mas também sobre o cosmos, mostrando que as negociações, as vantagens e desvantagens são relacionais e que ambos os lados são dotados de agência.

As prerrogativas de Tayana sobre os "materiais espirituais puros e impuros" também nos possibilitam refletir, à luz de Mary Douglas (1976), sobre as noções de pureza e impureza/perigo, pois quando a médium alerta que o uso de materiais espirituais impuros podem gerar consequências terríveis, sugere haver na impureza certa regulação das ordens sociais. Nessa regulação, o sagrado-profano deve se afastar de materiais que carregam forte carga genética e perecível daqueles que os usam: sangue menstrual, esperma e suor, que, em contato com os seres cósmicos, podem causar sentimentos de obsessão/posse por parte das entidades que participam do impulso erótico e desequilibrar as negociações. Durante a pesquisa de campo, me deparei com relatos como o da médium Ellen:

Tem também alguns feitiços que assim... São muito nojentos (risos), eu recomendo pra quem tem coragem, mas são muito fortes, mexem com forças absurdas que é muito difícil até para o médium deter. Uma é o sangue da menstruação! Coloca um pouco numa bebida forte, concentra ali toda a tua energia, a pessoa fica querendo saber só de ti, de mais ninguém! [...] Tem também com o esperma e essa eu te falo que eu mesma já fiz, me arrependo até hoje. (...) Primeiro eu amansei ele com esses mais simples, perfume de tamaquaré, essas coisas... Então depois que ele já tava fazendo só as minhas vontades eu pedi pra ele pra gente transar de camisinha, a gente não usava né Bruno?! Então eu tinha que amansar primeiro pra que ele não suspeitasse, porque ele sabia que eu sempre fui metida com essas coisas. Então eu peguei a camisinha, juntei ela com um monte de porcaria: 
tamaquaré, uruá... Coloquei tudo dentro da concha do uruá e fui numa cuieira, peguei uma cuia bem verde, abri, coloquei dentro e enterrei depois de deixar do lado de uma vela com formato de pênis cortada no meio. Daí o pau dele só subia comigo, com ninguém mais... Eu percebia que tinha dado certo porque ele tava diferente, dava pra ver que ele tinha tentado me trair de novo e não tinha conseguido (Entrevista com Ellen, setembro de 2017).

Muito embora Tayana tenha informado que o sangue e esperma sejam materiais espirituais impuros e não recomendados para a utilização em patuás, pois apodrecem e o amor ou desejo que se pretende também seria apodrecido, a médium Ellen recomenda a utilização desde que se tenha "coragem". Em nenhum momento, Ellen elenca as palavras "pureza" ou "impureza" com relação aos materiais espirituais, de modo que as noções do puro e impuro são estabelecidas de acordo com cada médium a partir de princípios ou dilemas morais. Como bem aponta Kelson Chaves (2010), as práticas de interferência em questões amorosas não possuem uma regra, mas são condicionadas ao jogo da moralidade entre médium, entidade, práticas e clientes. Ellen apresenta uma questão fundamental sobre o uso deste tipo de material espiritual, ao dizer que uma de suas consequências é tornar a pessoa "um escravo em vida", que é o ato de rebaixar o indivíduo à abjeção das suas próprias vontades para a satisfação das vontades alheias, indo de encontro ao dito por Tayana, de que a humilhação faz parte também do processo de obtenção de afeto/sexo pelo cosmos.

No contexto do cosmoerotismo amazônico, as práticas de rebaixamento podem acontecer quando se busca um patuá com o objetivo de humilhar outrem, o que chamei de humilhação intencional, ou seja, a busca por um patuá não como forma de conquistar alguém, mas como remédio a uma ferida moral, um ressentimento. O objetivo é fazer com que um possível algoz se sinta como a sua vítima, em uma perspectiva de vingança, um instrumento por excelência da humilhação. Para Lindner (2001), toda humilhação gera um desejo de retaliação.

A vingança via feitiço abre brechas para que um dentre os envolvidos se sinta mais humilhado que outro quando a "mironga" é descoberta, estabelecendo certa dialética da humilhação. Um novo ato de rebaixamento é alçado como uma tentativa de anulação da humilhação provocada por outrem, ou transforma-se em violência física/moral/letal com, até onde se sabe, outro feitiço, tal qual a literatura antropológica clássica de Evans-Pritchard (2005) sobre feitiçaria como um sistema de acusação, onde um se sente mais prejudicado que outro.

Eu sempre aconselho a mandar de volta, pois eu penso "se a pessoa te machucou, se ela fez algo pra você sofrer, ela também deve sofrer". Então quando me procuram pra desmanchar eu dou o conselho de mandar de volta. Agora mesmo eu estou mandando de volta a amarração que uma mulher fez pro ex-marido, ela está no Rio de Janeiro e ele aqui, ela queria vê-lo humilhado, sem emprego, sem libido e correndo atrás dela. Ele me procurou, e olha que ele é evangélico, fizemos uma consulta e percebi que 
ela tinha mandado amarrar ele. Então perguntei se ele queria se vingar e como ele queria, se queria só que ela sofresse a humilhação que ele sofreu ou se ele queria algo a mais. Ele disse que queria ela sofrendo e morta, então infelizmente ela vai morrer, eu não posso fazer nada, o direito é dele, a vingança é um direito de quem sofre (Entrevista com Denis, fevereiro de 2018).

Para Denis, o sujeito humilhado pode se vingar pelo feitiço da maneira que achar que deve. Uma vez que teve a sua dignidade/honra violada, ninguém deve interferir na forma como a pessoa deseja ser vingada. Portanto, se um sujeito que foi humilhado deseja pôr fim à vida de quem lhe causou esta humilhação, esta reivindicação torna-se um direito e o médium não interfere na forma, visto que somente quem viveu aquilo pode determinar o peso de seu sofrimento. Todavia, diversas são as controvérsias envolvidas, pois cada médium pode estabelecer sua conduta moral diante desses casos. Denis opta pela não interferência, Tayana alega se recusar a realizar trabalhos que não sejam "para o bem" ou que podem sobrecarregá-la posteriormente com o peso da culpa.

A humilhação como consequência não tem a prática do rebaixamento como fim, mas como um possível meio de conseguir seus objetivos. Explico: o intuito com o uso de uma defumação de "sexo da bota" pode ser melhorar o desempenho sexual, não para "ter alguém aos seus pés", menos ainda alguém específico. Há casos em que o uso da defumação está para o fortalecimento do self daquela/e que o faz, mas pode acontecer de alguém se apaixonar pela pessoa que utiliza o patuá apenas para si e essa pessoa não retribuir o afeto, fazendo com que haja perseguição e humilhação pelo enfeitiçamento por acaso.

Denis alerta que optar por utilizar um patuá é ter ciência (mas nem sempre) de que satisfazer seus impulsos eróticos ou necessidades urgentes pode significar favorecer a si a partir da humilhação amorosa do outro, mesmo que de maneira não intencional. Há, no entanto, formas diferentes (e desiguais) de sentir a humilhação, sobretudo na esfera pública das relações cotidianas, as quais aponto nas palavras que encerram este texto.

\section{O espetáculo no cotidiano: gênero e humilhação}

Quando as emoções estão imersas em relacionamentos afetivo-sexuais, há outros marcadores e outras emoções a serem evidenciados, como a relação entre gênero e os sentimentos hostis. Homens e mulheres participam e produzem a partir da interação com os afetos e sentimentos hostis complexos emocionais que agrupam diversos sentimentos operando nas dinâmicas sociais de modo articulado, estabelecendo suas micropolíticas (Coelho, 2010). Quem procura por um patuá o faz por uma motivação emocional, um desejo gentil ou hostil; e o uso acarreta consequências que encaminham para a humilhação e para uma interação pública entre ato de usar um patuá o ato humilhante gerado.

Na ordem privada, a humilhação é dotada de um caráter relacional que a situa 
de acordo com o tempo e espaço, mas de modo subjetivo para a pessoa que sofreu $o$ ato. Estes aspectos subjetivos e bem circunscritos espaço-temporalmente vem à tona, sobretudo, quando a humilhação atinge a esfera da vida pública e, sobretudo, quando está marcada pelas relações hierárquicas de gênero, raça ou sexualidade. Vivemos uma imersão na espetacularização da humilhação a partir de um conjunto técnico, estético e simbólico que possibilita a interação entre quem protagoniza o espetáculo e o espectador. Um crescente incentivo às jocosidades dos atos humilhantes está presente cada vez mais em pegadinhas, videocassetadas e demais programas de entretenimento, sugerindo que assistir à humilhação do outro se tornou prática corriqueira (Díaz-Benítez, 2015; 2019).

Mais que um afã pelo espetáculo da humilhação no cotidiano, parece haver demasiada repetição da interação entre espectadores e espetáculo, sugerindo que as formas cotidianas são repetidas rotineiramente num mesmo espaço. O que, para Armindo Bião (2009 p. 94), se trata da identificação prévia dos participantes do espetáculo da vida cotidiana "reconhecíveis socialmente por seus figurinos, adereços e posturas corporais, por suas formas de expressão vocal e gestual, reveladoras de estados de consciência e de corpo, simultaneamente de teatralidade e espetacularidade”. Quando em Abaetetuba são feitas acusações de "canoa" ou de "feiticeira" para que as jocosidades deem início ao espetáculo, estas somente são possíveis por haver características do que se convencionou chamar de "canoa" ou "feiticeira", estando o comportamento humano moldado de acordo com a expectativa do espectador.

Observa-se uma série de desigualdades no sentir a humilhação pública: mulheres são vistas como incapazes de conquistar homens ou são vistas pela ótica da promiscuidade num constante processo de estigmatização anterior ao acionamento dos feitiços e de uma rede de cosmoerotismos - os estigmas de solteironas e coitadinhas baseados no imaginário de que as mulheres necessitam casar-se, ter filhos e cuidar de seus homens. O feitiço, quando mantido em segredo por parte dessas mulheres, parece oferecer mobilidade e possibilidade de jogo com as hierarquias estabelecidas pela dominação simbólica (Bourdieu, 2007) a partir das tradições e do resgate da humanidade conferida aos animais não humanos tidos como submissos, por intermédio das entidades e de uma cosmologia amplamente partilhada pelo grupo social.

Mas, se por um lado às mulheres se reserva a possibilidade do jogo com as hierarquias, os relatos apresentados sobre vinganças reforçam o que Díaz-Benítez (2019) nos informa sobre confiança, de que homens e mulheres confiam de formas diferentes. Enquanto todos os casos relatados sobre vingança por parte das mulheres conferem o estabelecimento de feitiços não letais, o caso relatado de vingança masculina confere o prazer pela hierarquia, quando se sugere a morte como vingança a uma mácula na honra. A humilhação aqui não somente se estabelece de forma distinta entre os gêneros, mas a intersecção entre ato humilhante e o gênero de quem sofre o ato dá a um o aval de matar e ao outro o de apenas fazer sofrer, mas deixar viver.

Quanto aos desdobramentos e às narrativas construídas a partir da encomen- 
da da cliente à Tayana, não temos conhecimento, pois isso depende de como Débora fez uso não somente do preparado, mas dos aconselhamentos da médium. Mas é certo, pelo que foi narrado, que o atendimento aos impulsos eróticos na vida de algumas pessoas em Abaetetuba partilha de dinâmicas situadas num tempo-espaço amazônida, em que as interações humanas necessitam ser partilhadas com os outros seres que habitam os mundos das Amazônias. O pensamento que aqui compartilho possibilita entender os complexos emocionais que se relacionam e estabelecem suas micropolíticas, sem deixar de considerar outras formas de agências, sendo a magia a que neste escrito ganha destaque. Uma emoção gentil ou um desejo por melhorias no campo sexual tem também o potencial de mobilizar uma gama de outras emoções, dentre as quais as hostis, sendo essas mediadas pelo poder que aqui se apresenta de formas distintas e, a partir de diferentes agentes, age na esfera da vida privada/secreta mas também com interfaces públicas.

Na interação pública, os patuás atrativos perambulam entre ser uma materialidade das representações pitorescas/folclóricas do que se convencionou chamar de cultura amazônica e os desdobramentos dos seus usos na vida cotidiana de quem partilha da interpretação desses signos. Operam como importantes elementos da organização social, e mais que isso, conduzem o pensamento sobre a região para além da esfera representacional, pois estão entrelaçados a uma condição cosmológica, difundida na prática, adaptando-se aos contextos e às formas subjetivas da interação entre os sujeitos. 


\section{Referências}

ALBUQUERQUE, Maria Betânia Barbosa; FARO, Mayra Cristina Silva. Saberes de cura: um estudo sobre a pajelança cabocla e mulheres pajés da Amazônia. Revista Brasileira de História das Religiões, v. 5, n. 13, p. 57-72, 2012.

AMOROZO, Maria Christina de Mello; MING, Lin Chau; SILVA, Sandra Maria Pereira (Eds.). Métodos de coleta e análise de dados em Etnobiologia, Etnoecologia e disciplinas correlatas. In: I Seminário de Etnobiologia e Etnoecologia do Sudeste. Anais..., Rio Claro, 2002.

BARROS, Flávio Bezerra. E a bota encantou o homem que dormia na rede. In: SOUTO, Francisco José Bezerra; DUQUE-BRASIL, Reinaldo; SOLDATI, Gustavo Taboada; MING, Lin Chau; COELHO, France Maria Gontijo; ALENCAR, Nelson Leal (Orgs.). Quando pensa que não... contos, causos e crônicas em Etnoecologia. v. 2. Feira de Santana: Z-Arte Editora, v. 2, p. 143-145, 2016.

BARROS, Flávio Bezerra; VARELA, Susana; PEREIRA, Henrique; VICENTE, Luís. Medicinal use of fauna by a traditional community in the Brazilian Amazonia. Journal of Ethnobiology and Ethnomedicine, v. 8, n. 37, p. 1-19, 2012.

BELAUNDE, Luisa Elvira. Resguardo e sexualidade(s): uma antropologia simétrica das sexualidades amazônicas em transformação. Cadernos de Campo, v. 24, p. 538-564, 2015.

BIÃO, Armindo. Etnocenologia e a cena baiana: textos reunidos. Salvador: P\&A, 2009.

BITENCOURT, Bruna Letícia Gentil; LIMA, Pedro Glécio Costa; BARROS, Flávio Bezerra. Comércio e uso de plantas e animais de importância mágico-religiosa e medicinal no Mercado Público do Guamá, Belém do Pará. Revista FSA, v. 11, n. 3, p. 96-158, 2014.

BOURDIEU, Pierre. A dominação masculina. Trad. de Maria Helena Kühner. 5. ed. Rio de Janeiro: Bertrand Brasil, 2007.

CHAVES, Kelson. Os trabalhos de amor e outras mandingas: as experiências mágico-religiosas em terreiros de umbanda. Dissertação (Mestrado em Ciências Sociais) Universidade Federal do Rio Grande do Norte, Natal, 2010.

COELHO, Maria Cláudia. Narrativas da Violência: a dimensão micropolítica das emoções. Mana, v. 16, n. 52, p. 265-285, 2010.

DÍAZ-BENÍTEZ, María Elvira. O espetáculo da humilhação: fissuras e os limites da sexualidade. Mana, v. 21, n. 1, p. 65-90, 2015.

DÍAZ-BENÍTEZ, María Elvira. O gênero da humilhação. Afetos, relações e complexos emocionais. Horizontes Antropológicos, v. 25, n. 54, p. 51-78, 2019.

DOMINGUES, Bruno Rodrigo Carvalho. Entre tradição, desejo e poder: uma Amazônia Cosmoerótica. Trabalho de Conclusão de Curso (Graduação em Ciências Sociais) Universidade Federal do Pará, Belém, 2019.

DOUGLAS, Mary. Pureza e Perigo. São Paulo: Perspectiva, 1976.

EVANS-PRITCHARD, Edward. Bruxaria, oráculos e magia entre os Azande. Rio de Janeiro: Zahar, 2005.

FIGUEIREDO, Aldrin Moura de. A cidade dos encantados: pajelanças, feitiçarias e religiões afro-brasileiras na Amazonia; a constituição de um campo de estudo 1870-1950. Dissertação (Mestrado em História) - Universidade Estadual de Campinas, Campi- 
nas, 1996.

FIGUEIREDO, Napoleão. Os "bichos" que curam: os animais e a medicina de "folk" em Belém do Pará. Boletim do Museu Paraense Emílio Goeldi, série Antropologia, v. 10, n. 1, p. 75-91, 1994.

FRAXE, Terezinha de Jesus. Cultura cabocla-ribeirinha: mitos, lendas e transculturalidade. São Paulo: Annablume, 2004.

GALVÃO, Eduardo. Santos e visagens - um estudo da vida religiosa de Itá, Amazonas. São Paulo: Companhia Editora Nacional, 1955.

GOFFMAN, Erving. A representação do eu na vida cotidiana. Petrópolis: Vozes, 2009.

GOFFMAN, Erving. Estigma: notas sobre a manipulação da identidade deteriorada. Trad. de Mathias Lambert. Rio de Janeiro: LTC, 1988.

INGOLD, Tim. Humanidade e Animalidade. Trad. de Vera Pereira. Londres: Routledge, 1994. (Companion Encyclopedia of Anthropology).

LINDNER, Evelin G. Humiliation and the human condition: mapping a minefield. Human Rights Review, v. 2, n. 2, p. 46-63, 2001.

LOPES, Ana Débora Silva. A cura que vem da natureza: conhecimentos, práticas e apreensões da biodiversidade por beiradeiros da Estação Ecológica Terra do Meio, Amazônia Brasileira. Dissertação (Mestrado em Antropologia) - Universidade Federal do Pará, Belém, 2015.

LOUREIRO, João Jesus Paes. A conversão semiótica na arte e na cultura. Belém: EDUFPA, 2007.

LOUREIRO, João Jesus Paes. Cultura amazônica: uma poética do imaginário. São Paulo: Escrituras, 2001.

MALINOWSKI, Bronisław. Argonautas do Pacífico Ocidental: um relato do empreendimento e de aventura dos arquipélagos da Nova Guiné Melanésia. São Paulo: Abril Cultural, 1978.

MAUÉS, Raymundo Heraldo. Padres, pajés, santos e festas: catolicismo popular e controle eclesiástico - um estudo antropológico numa área do interior da Amazônia. Belém: Cejup, 1995.

MELO, Maíra Fernanda Tavares; BARROS, Flávio Bezerra. O mundo segundo os quilombolas do bairro alto (Ilha de Marajó): cosmovisões acerca da vida e das relações sociedade e natureza. ACENO, v. 3, n. 6, p. 51-78, 2016.

MOTTA-MAUÉS, Maria Angélica. "Lugar de mulher": representações sobre os sexos e práticas médicas na Amazônia (Itapuá/Pará). In: ALVES, Paulo Cesar; MINAYO, Maria Cecília de Souza (Orgs.). Saúde e doença: um olhar antropológico. Rio de Janeiro: Editora FIOCRUZ, 1994.

PINTO, Benedita Celeste de Moraes. Parteiras, experientes e poções: o dom que se apura pelo encanto da floresta. Tese (Doutorado em História) - Pontifícia Universidade Católica de São Paulo, São Paulo, 2004.

SILVA JUNIOR, Fernando Alves da. Representação feminina no mito da matintaperera em Taperaçu Campo, Bragança (PA). Dissertação (Mestrado em Linguagem e Saberes da Amazônia) - Universidade do Estado do Pará, Bragança, 2014.

SILVA, Jerônimo da Silva e. Cartografia de afetos na encantaria: narrativas de Mestres da Amazônia Bragantina. Tese (Doutorado em Antropologia) - Universidade do Estado do Pará, Belém, 2014. 
SILVA, Lucielma Lobato. Gênero, religião e simbolismo: um estudo do tabu do sangue nas religiões de matriz africana em Abaetetuba - Pará. Dissertação (Mestrado em Ciências da Religião) - Universidade do Estado do Pará, Belém, 2013.

SILVEIRA, Flávio Leonel Abreu; SOUZA, Cassio Silva. Imaginário, trabalho e sexualidade entre os coletores de caranguejo do Salgado Paraense. Estudos Feministas, v. 22, n. 3, p. 320, 2014.

SMEDSLUND, Jan. The structure of psychological common sense. Mahwah, New Jersey: Lawrence Erlbaum Associates, 1997.

VERGUEIRO, Viviane. Por inflexões decoloniais de corpos e identidades de gênero inconformes: uma análise autoetnográfica da cisgeneridade como normatividade. Dissertação (Mestrado em Cultura e Sociedade) - Universidade Federal da Bahia, Salvador, 2016.

VICENTINI DE AZEVEDO, Ana. Da humilhação à sublimação: a via da fantasia na psicanálise e na literatura. In: MARSON, Izabel; NAXARA, Márcia (Orgs.). Sobre humilhação. Sentimentos, gestos, palavras. Uberlândia: EDUFU, 2005. p. 49-83. 